\title{
PULMONARY BLOOD FLOW REGULATES PLASMA TISSUE PLASMINOGEN ACTIVATOR CONCENTRATIONS IN PATIENTS WITH CONGENITAL HEART DEFECTS
}

\author{
Akira Mishima, MD \\ Miki Asano, MD \\ Takayuki Saito, MD \\ Shigeki Yamamoto, MD \\ Tomohiko Ukai, MD \\ Hirohisa Yoshitomi, MD \\ Kozo Matsumoto, MD \\ Tadao Manabe, MD
}

\begin{abstract}
Objective: The wall shear stress generated by blood flow regulates the expression of fibrinolytic proteins by endothelial cells in vitro. In the present study, the effects of pulmonary blood flow on fibrinolytic activity were studied in patients with congenital heart defects and pulmonary hypertension. Methods: Twenty-seven patients who underwent cardiac operation because of congenital heart defects were divided into four groups according to the severity of pulmonary hypertension. Group I consisted of seven patients with normal pulmonary artery pressure, group II consisted of nine patients with pulmonary hypertension caused by increased pulmonary blood flow, group III consisted of six patients with pulmonary hypertension caused by increased pulmonary vascular resistance, and group IV consisted of five patients with tetralogy of Fallot. Plasma concentrations of tissue plasminogen activator, plasmin, and thrombin were assayed as the inhibitor-bound forms. Results: The preoperative concentration of tissue plasminogen activator was higher in group II than in all other groups $(p=\mathbf{0 . 0 0 0 3})$. However, the postoperative concentration decreased only in patients in group II when compared with the preoperative value $(p=0.01)$. By Pearson's correlation analysis, pulmonary blood flow was found to correlate with the preoperative concentration of tissue plasminogen activator $(95 \%$ confidence interval $=3.99$ to $10.58, p=$ 0.0001 ). No definite conclusion was found for the relationship between tissue plasminogen activator and plasmin concentration. Further, the preoperative thrombin concentration was similar in all groups. Conclusions: These findings suggest that pulmonary blood flow may regulate the plasma concentration of tissue plasminogen activator in patients with congenital heart defects. (J Thorac Cardiovasc Surg 1997;113:742-7)
\end{abstract}

$H^{\circ}$ emodynamic forces have been shown to influence the structure and function of vascular endothelial cells. ${ }^{1-4}$ Endothelial cells respond to mechanical stress by altering gene expression and by undergoing significant structural reorganization. ${ }^{5}$ Specifically, the endothelial cell is the primary source of tissue plasminogen activator $(\mathrm{t}-\mathrm{PA})^{6}$ and is also responsible for the production of several plasminogen activator inhibitors. It has already been

From the First Department of Surgery, Nagoya City University Medical School, Nagoya, Japan.

Received for publication June 13, 1996; revisions requested August 5, 1996; revisions received Oct. 21, 1996; accepted for publication Oct. 22, 1996.

Address for reprints: Akira Mishima, MD, The First Department of Surgery, Nagoya City University Medical School, 1 Kawasumi, Mizuho-cho, Mizuho-ku, Nagoya, 467 Japan.

Copyright (C 1997 by Mosby-Year Book, Inc.

$0022-5223 / 97 \$ 5.00+0 \quad \mathbf{1 2 / 1 / 7 8 7 5 9}$ reported that fluid shear stress increases t-PA at both the protein ${ }^{7}$ and messenger ribonucleic acid ${ }^{8}$ levels of endothelial cells in vitro.

Patients with congenital heart defects with left-toright shunting of blood often have pulmonary hypertension as a result of increased pulmonary blood flow. In some patients, this results in a progressive increase in pulmonary vascular resistance. 9.10 The severity of the pulmonary vascular changes determines the patient's prognosis and the outcome of surgical intervention. Increased pulmonary blood flow is believed to increase fluid shear stress on the endothelial surface of the lung. Endothelial cells may initially respond to these hemodynamic changes by altering their structure and function to maintain adequate pulmonary circulation. Although fibrinolytic activity is recognized as important in this adaptation, few studies of the interaction between fibrinolytic activity and hemodynamic forces in 


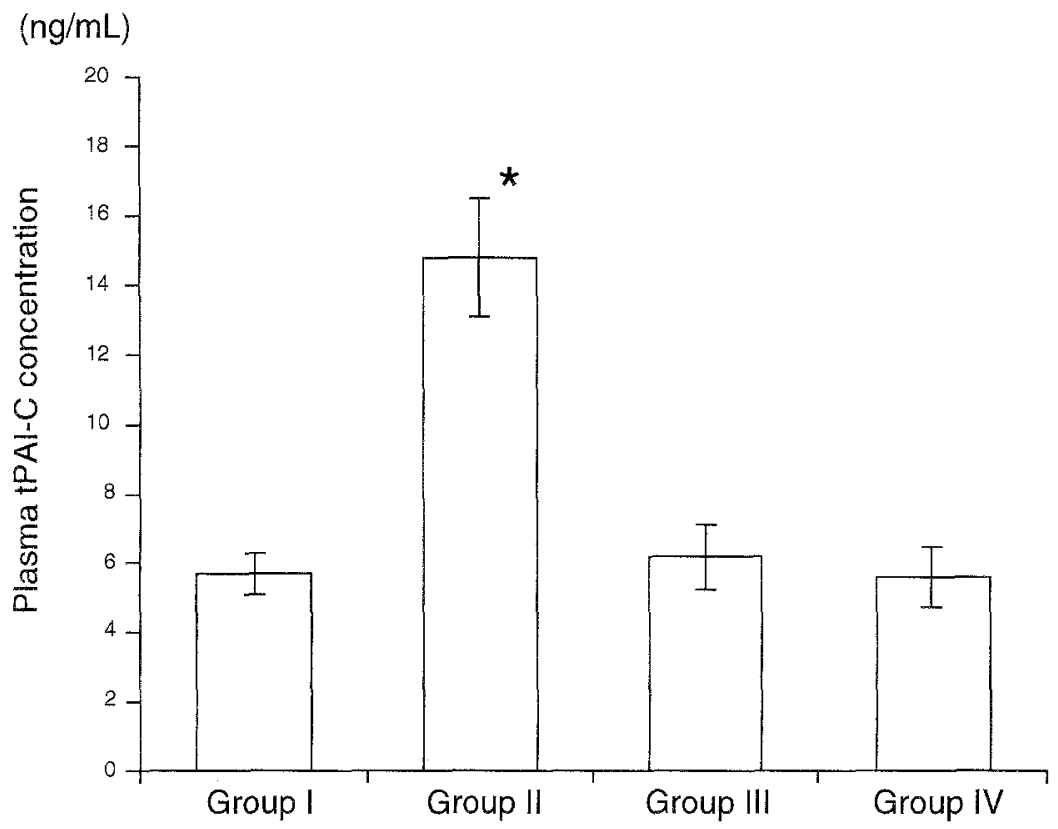

Fig. 1. Preoperative plasma tPAI-C concentrations. The mean plasma concentration for group II was higher than the values for the other three groups. There was no statistical difference between groups I, III, and IV. Values are mean plus or minus the standard error of the mean. " $p=0.0001$ versus group I; ${ }^{*} p=$ 0.0003 versus groups III and IV.

patients with congenital heart defects have been reported. To investigate the role of pulmonary blood flow in fibrinolytic activity in patients with congenital heart defects and pulmonary hypertension, we examined plasma concentrations of t-PA, plasmin, and thrombin before and after cardiac operations.

\section{Patients and methods}

Twenty-seven children with congenital heart defects who underwent intracardiac repair between November 1994 and May 1995 were included in the study. The ages at the time of operation ranged from 1 month to 3 years (median age, 9 months). The diagnoses included ventricular septal defect (12 patients, with associated coarctation of the aorta in 2 patients), tetralogy of Fallot ( 5 patients), atrioventricular septal defect (4 patients), and doubleoutlet right ventricle ( 2 patients). The remaining four patients had a variety of congenital defects. Twenty-two patients excluding those with tetralogy of Fallot were divided into three groups according to the severity of pulmonary hypertension, which was evaluated by cardiac catheterization one half month to 5 months before operation. Group I consisted of seven patients with normal or slightly increased pulmonary arterial pressure (the ratio of pulmonary artery to aortic systolic pressure $[\mathrm{Pp} / \mathrm{Ps}] \leq 0.5$ ), group II consisted of nine patients with pulmonary hypertension caused by increased pulmonary blood flow ( $\mathrm{Pp} / \mathrm{Ps}$ $>0.5$; the ratio of pulmonary to systemic blood flow
Table I. Ratios for pressure, flow, and resistance

\begin{tabular}{lccc}
\hline \multicolumn{1}{c}{ Variable } & Group I & Group II & Group II \\
\hline $\mathrm{n}$ & 7 & 9 & 6 \\
Pressure (Pp/Ps) & $0.33 \pm 0.1$ & $0.94 \pm 0.07$ & $0.92 \pm 0.07$ \\
Flow (Qp/Qs) & $1.64 \pm 0.34$ & $3.35 \pm 1.08$ & $1.31 \pm 0.39$ \\
Resistance (Rp/Rs) & $0.13 \pm 0.01$ & $0.28 \pm 0.09$ & $0.73 \pm 0.15$ \\
\hline
\end{tabular}

Values are mean plus or minus the standard deviation.

volume $[\mathrm{Qp} / \mathrm{Qs}]>2$ ), and group III consisted of six patients with pulmonary hypertension caused by elevation in pulmonary vascular resistance ( $\mathrm{Pp} / \mathrm{Ps}>0.5, \mathrm{Qp} / \mathrm{Qs} \leq 2)$. Group IV was a control group (tetralogy of Fallot) and consisted of five patients with decreased pulmonary blood flow.

The ratios for pressure, flow, and resistance in groups I, II, and III are shown in Table I. All cardiopulmonary bypass (CPB) procedures were done at moderate hypothermia with crystalloid cardioplegia. The CPB times ranged from 82 to 339 minutes (mean plus or minus standard deviation, $183.9 \pm 76.1$ minutes), including circulatory assistance time with CPB.

Arterial blood samples were obtained from all patients before operation and 1 hour after CPB. Venous blood samples were obtained 4 to 13 months after the operation from 14 patients, including 1 in group I, 5 in group II, 5 in group III, and 3 in group IV (those patients who were followed up at our department). Plasma was separated by centrifugation at $4^{\circ} \mathrm{C}$, immediately frozen, and stored at 


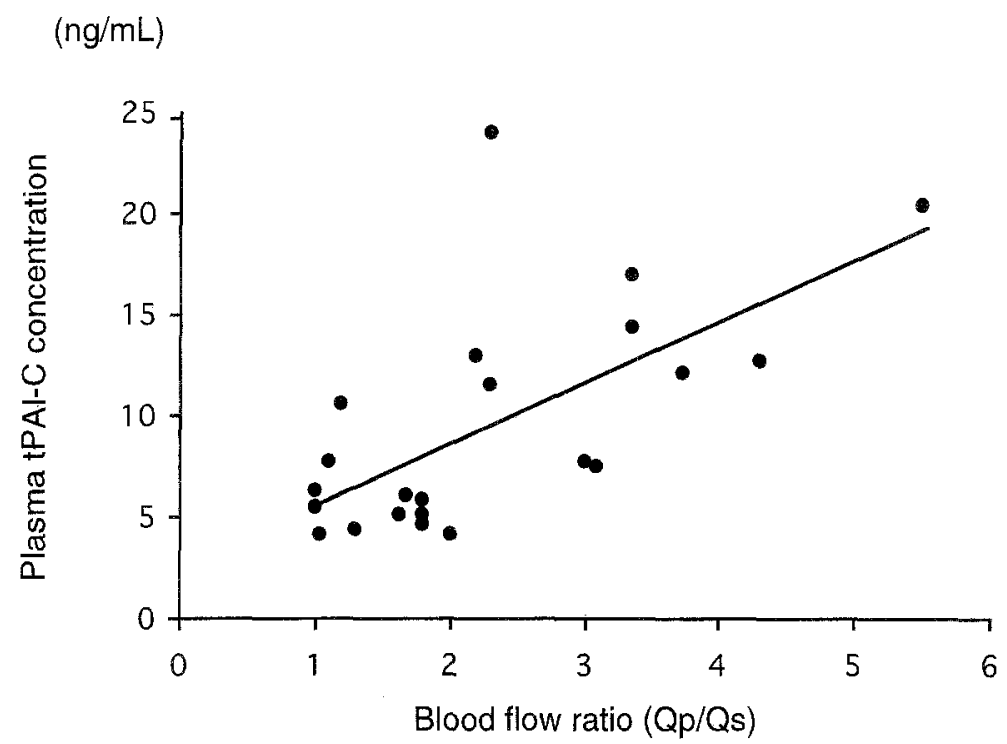

Fig. 2. Distribution of the preoperative plasma $\mathrm{tPAI}-\mathrm{C}$ concentration and pulmonary flow ratio (Qp/Qs) in 22 patients in groups I, II, and III. The data showed a correlation between the preoperative tPAI-C concentration and pulmonary blood flow: $r=0.65,95 \%$ confidence interval $=0.32$ to $0.83, p=0.001$.

Table II. Effect of pulmonary blood flow on the preoperative plasma $t P A I-C$ concentration

\begin{tabular}{ccccc}
\hline Variable & $\beta$ & $S E$ & $95 \%$ CI & $p$ Value \\
\hline Pulmonary pressure $(\mathrm{Pp} / \mathrm{Ps})$ & 1.928 & 1.549 & -1.263 to 5.129 & 0.2255 \\
Pulmonary flow $(\mathrm{Qp} / \mathrm{Qs})$ & 7.282 & 1.594 & 3.998 to 10.565 & 0.0001
\end{tabular}

Pulmonary hypertension and high pulmonary blood flow were defined as $\mathrm{Pp} / \mathrm{Ps}>0.5$ and $\mathrm{Qp} / \mathrm{Qs}>2$, respectively. SE, Standard error; $C I$, confidence interval. Pearson's correlation analysis was used. $p$ Value for the model: $0.0001, \mathrm{R}$-square: 0.623 .

$-60^{\circ} \mathrm{C}$. Informed consent for blood sampling was obtained from the parents of each child.

Plasma concentrations of t-PA, plasmin, and thrombin were assayed as inhibitor-bound forms: t-PA-plasminogen activator inhibitor 1 complex (tPAI-C), plasmin- $\alpha_{2}$ plasmin inhibitor complex (PIC), and thrombin-antithrombin III complex (TAT). Plasma concentrations of tPAI-C and PIC were measured with the use of commercially available enzyme-linked immunosorbent assay kits (Teijin Ltd., Japan). ${ }^{11,12}$ Plasma concentrations of TAT were also determined with an enzyme-linked immunosorbent assay kit (Behringwerke, Germany). ${ }^{13}$

Statistical analysis was done with Statistical Analysis Systems software for the personal computer (SAS Institute, Cary, N.C.). Values for quantitative variables were expressed as the mean plus or minus the standard error of the mean except for those in Table I. Statistical differences among the groups were determined by the permutation test. Changes in the values of variables were compared by the paired Student's $t$ test. A correlation matrix was used to determine the relationship between two variables. To determine independent predictors of plasma tPAI-C concentration, pulmonary artery pressure and pulmonary blood flow values were subjected to Pearson's correlation analysis. The $95 \%$ confidence interval and the actual $p$ value were reported. Statistical significance was accepted at a level of $p<0.05$ (two-sided tests).

\section{Results}

The preoperative plasma tPAI-C concentrations for each group are depicted graphically in Fig. 1. The mean plasma $\mathrm{PAI}-\mathrm{C}$ concentration for group II was greater than those of all other groups $(14.8 \pm$ 1.7 vs 5.6 to $6.2 \pm 0.6$ to $0.9 \mathrm{ng} / \mathrm{ml}, p=0.0001$ to $0.0003)$. The preoperative plasma tPAI-C concentrations correlated with the pulmonary flow ratio (Qp/Qs) in groups I, II, and III as shown in Fig. 2 $(p=0.001)$. On the basis of Pearson's correlation analysis, pulmonary blood flow was proportional to the preoperative plasma concentration of tPAI-C $(p=0.0001)$; however, pulmonary artery pressure was not proportional ( $p=0.23$ ) (Table II). One hour after CPB, concentrations of tPAI-C increased in all patients with the mean $\mathrm{PAI}-\mathrm{C}$ concentration increasing from $8.5 \pm 1.1$ to $20.6 \pm 2.0 \mathrm{ng} / \mathrm{ml}(p=$ $\left.2.5 \times 10^{-7}\right)$. The plasma tPAI-C concentration after 


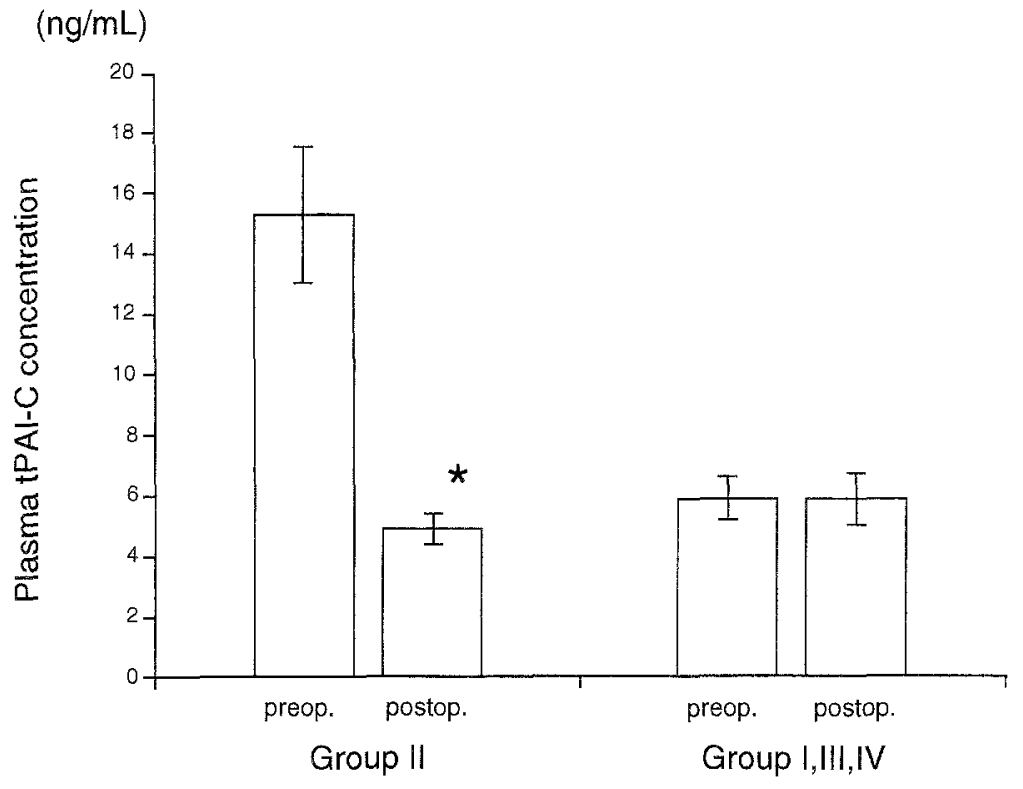

Fig. 3. Changes in the plasma tPAI-C concentration in response to intracardiac repair. The postoperative plasma tPAI-C concentration was measured in 14 patients 4 to 13 months after the operation. The postoperative concentration for group II was lower than the preoperative concentration. Values are mean plus or minus the standard error of the mean. ${ }^{*} p=0.01,95 \%$ confidence interval $=-16.73$ to -4.06 by Student's paired $t$ test comparing preoperative and postoperative values.

CPB correlated with CPB time $(r=0.52,95 \%$ confidence interval $=0.16$ to $0.76, p=0.008$ ). Four to 13 months after intracardiac repair, tPAI-C concentrations for groups I, III, and IV $(n=9)$ returned to preoperative levels and those for group II $(n=5)$ decreased from preoperative levels to $4.9 \pm 0.5 \mathrm{ng} / \mathrm{ml}$ as shown in Fig. $3(p=0.01)$. There were no statistical differences in the tPAI-C concentrations among the four groups after the operations $(p=0.82)$.

The mean plasma PIC concentration 1 hour after $\mathrm{CPB}$ increased compared with the preoperative value $(0.86 \pm 0.05$ vs $0.50 \pm 0.11 \mu \mathrm{g} / \mathrm{ml}, p=0.025)$. There was no statistical correlation between tPAI-C and PIC values either before operation $(r=-0.43$, $95 \%$ confidence interval $=-0.95$ to $0.72, p=0.46$ ) or after $\mathrm{CPB}(r=0.21,95 \%$ confidence interval $=$ -0.82 to $0.92, p=0.73$ ); however, no definite conclusion was obtained from these data. Preoperative plasma concentrations of TAT were similar between each group (group I, $7.4 \pm 2.7 \mathrm{ng} / \mathrm{ml}$; group UI, $7.9 \pm 2.7 \mathrm{ng} / \mathrm{ml}$; group III, $6.9 \pm 3.9 \mathrm{ng} / \mathrm{ml}$; and group IV, $4 \pm 0.5 \mathrm{ng} / \mathrm{ml}, p=0.75$ ).

\section{Discussion}

In patients with congenital heart defects and associated left-to-right shunting, the pulmonary vas- cular endothelial cells are subjected to mechanical forces out of the physiologic range. These forces include shear stress caused by increased pulmonary blood flow and mechanical strain caused by elevated pulmonary artery pressures. In the present study, we investigated fibrinolytic activity by plasma tPAI-C concentration in patients with congenital heart defects, who were divided into four groups according to pulmonary blood flow and pulmonary artery pressure. The presence of tPAI-C in plasma is a direct indicator of in vivo generation of t-PA. ${ }^{11,14}$ As the results demonstrate, increases in plasma tPAI-C concentrations depend on pulmonary blood flow and not on pulmonary artery pressure. When pulmonary blood flow returned to normal after the operation, the plasma concentration of tPAI-C in group II decreased to a level similar to those of the other three groups.

These findings demonstrate that high shear stress, produced by increased pulmonary blood flow in the setting of congenital heart defects, results in increased secretion of tPAI-C by stimulated pulmonary vascular cells. In previous experimental studies, fluid shear stress was found to stimulate t-PA secretion in cultured human endothelial cells ${ }^{7,8}$ and to downregulate endothelial expression of thrombo- 
modulin in cultured bovine aortic endothelial cells. ${ }^{15}$ Endothelial cells also synthesize prostacy$\operatorname{clin}^{16}$ and release nitric oxide ${ }^{17}$ when stimulated by shear stress. These bioactive agents serve to inhibit blood coagulation.

In 11 patients including three in group I, five in group II, and three in group III, shear stress $(\tau$, dynes per square centimeter) at the right pulmonary artery was calculated according to the following equation $^{18}$ :

$$
\tau=4 \mu \mathrm{Qp} / \pi \mathrm{r}^{3}
$$

where $\mu$ represents whole blood viscosity $(0.03 \mathrm{P})$, $\mathrm{Qp}$ is the flow rate of the right pulmonary artery (in milliliters per second), and $r$ is the internal radius of the right pulmonary artery (in centimeters). The value of shear stress was $3.6 \pm 1 \mathrm{dyn} / \mathrm{cm}^{2}$ in group $\mathrm{I}$, $6.1 \pm 1.2 \mathrm{dyn} / \mathrm{cm}^{2}$ in group II, and $3.8 \pm 1.5 \mathrm{dyn} / \mathrm{cm}^{2}$ in group III. The value statistically correlated with the preoperative plasma tPAI-C concentration $(r=$ $0.69,95 \%$ confidence interval $=0.15$ to $0.91, p=$ 0.02 ).

Plasma concentrations of tPAI-C after CPB increased in statistical correlation with $\mathrm{CPB}$ time in the present study. However, in four patients, in whom plasma tPAI-C concentrations in the pulmonary artery and vein were measured simultaneously 1 hour after CPB, there was no statistical difference between the values $(26 \pm 6.1$ vs $25.8 \pm 7.1 \mathrm{ng} / \mathrm{ml}$, $p=0.91)$. Therefore these increases might be caused by the endothelial response of systemic arteries to CPB.

It is well known that TAT and PIC are measures of thrombin and plasmin generation, respectively, ${ }^{19,20}$ and that the substrates for these complexes are synthesized in the liver. Therefore it seems reasonable that in patients with congenital heart defects the plasma TAT and PIC concentrations might not change irrespective of tPAI-C concentrations. The effect of shear stress on the production of coagulation factors by vascular endothelial cells has rarely been studied. Recently, it was reported that human umbilical vein endothelial cells subjected to fluid shear stress, when activated by interleukin- $1 \alpha$, are able to generate significant quantities of factor $\mathrm{Xa}^{21}$

Increased secretion of t-PA is thought to be a reactive change that results from high shear stress caused by increased pulmonary blood flow. Increased concentrations of t-PA may contribute to maintenance of pulmonary blood flow by inhibiting a thrombotic tendency. Once pulmonary vascular obstructive disease develops in patients with congenital heart defects, a reduction in pulmonary blood flow and in secretion of t-PA may result in a comparable prothrombotic situation.

Hemodynamic forces change the structure and function of pulmonary vascular endothelial cells. On the other hand, vascular changes, including endothelial cell changes, may affect the hemodynamics associated with congenital heart defects. In conclusion, our results suggest that shear stress generated by increased pulmonary blood flow may regulate the plasma concentrations of $\mathrm{APAI}-\mathrm{C}$ in patients with congenital heart defects. Increased concentrations of tPAI-C may be important to maintain pulmonary blood flow.

\section{REFERENCES}

1. Ookawa $\mathrm{K}$, Sato $\mathrm{M}$, Ohshima N. Changes in the microstructure of cultured porcine aortic endothelial cells in the early stage after applying a fluid-imposed shear stress. J Biomech 1992;25:1321-8.

2. Shen J, Luscinskas FW, Connolly A, Dewey CF Jr, Gimbrone MA Jr. Fluid shear stress modulates cytosolic free calcium in vascular endothelial cells. Am J Physiol 1992; 262:C384-90.

3. Malek AM, Izumo S. Control of endothelial cell gene expression by flow. J Biomech 1995;28:1515-28.

4. Davies PF. Flow-mediated endothelial mechanotransduction. Physiol Rev 1995;75:519-60.

5. Davies PF, Tripathi SC. Mechanical stress mechanisms and the cell: an endothelial paradigm. Circ Res 1993;72:239-45.

6. Huber K, Beckmann R, Frank H, Kneussi M, Mlczoch J, Binder BR. Fibrinogen, t-PA, and PAI-1 plasma levels in patients with pulmonary hypertension. Am J Respir Crit Care Med 1994;150:929-33.

7. Diamond SL, Eskin SG, McIntire LV. Fluid flow stimulates tissue plasminogen activator secretion by cultured human endothelial cells. Science 1989;243:1483-5.

8. Diamond SL, Sharefkin JB, Dieffenbach C, Frasier-Scott K, McIntire LV, Eskin SG. Tissue plasminogen activator messenger RNA levels increase in cultured human endothelial cells exposed to laminar shear stress. J Cell Physiol 1990;143:364-71.

9. Heath D, Edwards JE. The pathology of hypertensive pulmonary vascular disease. Circulation 1958;18:533-47.

10. Wagenvoort CA. Lung biopsy specimens in the evaluation of pulmonary vascular disease. Chest 1980;77:614-25.

11. Asakura H, Jokaji H, Saito M, et al. Changes in plasma levels of tissue-plasminogen activator/inhibitor complex and active plasminogen activator inhibitor in patients with disseminated intravascular coagulation. Am J Hematol 1991;36:176-83.

12. Mimuro J, Koike Y, Sumi Y, Aoki N. Monoclonal antibodies to discrete regions in $\alpha 2$-plasmin inhibitor. Blood 1987;69: 446-53.

13. Pelzer $\mathrm{H}$, Schwarz A, Heimburger N. Determination of human thrombin-antithrombin III complex in plasma with an enzyme-linked immunosorbent assay. Thromb Haemost 1988;59:101-6. 
14. Fukao H, Ueshima S, Okada K, Yamamoto K, Matsuo T, Matsuo $O$. Tissue-type plasminogen activator, type 1 plasminogen activator inhibitor and their complex in plasma with disseminated intravascular coagulation. Thromb Res 1992;68:57-65.

15. Malek AM, Jackman R, Rosenberg RD, Izumo S. Endothelial expression of thrombomodulin is reversibly regulated by fluid shear stress. Circ Res 1994;74:852-60.

16. Frangos JA, Eskin SG, McIntire LV, Ives CL. Flow effects on prostacyclin production by cultured human endothelial cells. Science 1985;227:1477-9.

17. Nishida K, Harrison DG, Navas JP, et al. Molecular cloning and characterization of the constitutive bovine aortic endothelial cell nitric oxide synthase. J Clin Invest 1992;90:2092-6.
18. Olesen S-P, Clapham DE, Davies PF. Haemodynamic shear stress activates a $\mathrm{K}+$ current in vascular endothelial cells. Nature 1988;331:168-70

19. Takahashi H, Tatewaki W, Wada K, Hanano M, Shibata A. Thrombin vs. plasmin generation in disseminated intravascular coagulation associated with various underlying disorders. Am J Hematol 1990;33:90-5.

20. Bauer KA, Rosenberg RD. The pathophysiology of the prethrombotic state in humans: insights gained from studies using markers of hemostatic system activation. Blood 1987; 70:343-50.

21. Grabowski EF, Zukerman DB, Nemerson Y. The functional expression of tissue factor by fibroblasts and endothelial cells under flow conditions. Blood 1993;81:3265-70.

\section{Bound volumes available to subscribers}

Bound volumes of The Journal of Thoracic and Cardiovascular Surgery are available to subscribers (only) for the 1997 issues from the Publisher, at a cost of $\$ 110.50$ for domestic, $\$ 139.64$ for Canadian, and $\$ 130.50$ for international subscribers for Vol. 113 (January-June) and Vol. 114 (July-December). Shipping charges are included. Each bound volume contains a subject and author index and all advertising is removed. Copies are shipped within 60 days after publication of the last issue of the volume. The binding is durable buckram with the Journal name, volume number, and year stamped in gold on the spine. Payment must accompany all orders. Contact Mosby-Year Book, Inc., Subscription Services, 11830 Westline Industrial Drive, St. Louis, Missouri 63146-3318, USA; phone $800-453-4351$ or $314-453-4351$.

Subscriptions must be in force to qualify. Bound volumes are not available in place of a regular Journal subscription. 